\title{
INGUINAL HERNIA REPAIR USING LIGHT AND HEAVY POLYPROPYLENE MESH: A COMPARATIVE STUDY
}

\author{
K. M. Ganesh Babu1, Rajashekar N², Nagaraj K. N33 \\ ${ }^{1}$ Assistant Professor, Department of General Surgery, MVJ Medical College, Hoskote, Bangalore. \\ 2 Post Graduate, Department of General Surgery, MVJ Medical College, Hoskote, Bangalore. \\ 3Professor, Department of General Surgery, MVJ Medical College, Hoskote, Bangalore.
}

\begin{abstract}
BACKGROUND

To compare and analyse the difference between heavy and light polypropylene mesh for the following outcomes- foreign body sensation, chronic pain, recurrence, patient postoperative recovery time and return to normal activities.

METHODS

Study includes patients admitted in Surgery Department, MVJ Medical College and Research Hospital, Hoskote, Bangalore, for Inguinal Hernia. A total of 60 patients studied who underwent Lichtenstein's mesh repair were divided into two groups of 30 each using randomization by equal allocation. The study period was from November 2014 to July 2015.
\end{abstract}

\section{CONCLUSION}

The comparative study between light and heavy polypropylene mesh in Lichtenstein's mesh repair for inguinal hernia showed Light mesh is superior to Heavy mesh in terms of lesser stiffness over abdominal wall postoperatively, lesser foreign body sensation, lesser severity of chronic pain, whereas heavy mesh had lower recurrence rates as compared to light mesh.

\section{KEYWORDS}

Lichtenstein, Hernia, Polypropylene, Comparative, Heavy, Light, Mesh Repair.

HOW TO CITE THIS ARTICLE: Babu KMG, Rajashekar N, Nagaraj KN. Inguinal hernia repair using light and heavy polypropylene mesh: a comparative study. J. Evolution Med. Dent. Sci. 2016;5(23):1221-1224, DOI: 10.14260/jemds/2016/285

\section{INTRODUCTION}

Inguinal hernia repair is one of the most common surgical procedures performed in practice. Although numerous techniques have been described, currently tension free mesh repair is the standard of care in the treatment of hernias because of the low recurrence rates. However, chronic pain, foreign body sensation, stiff lower abdominal wall have been variably reported in patients. Experimental studies have hypothesized that the inflammatory reaction and scar tissue formation caused by the mesh is responsible for the high incidence of postoperative pain.

Today, the meshes used are typically made from polypropylene. The original first generation of the meshes described for the treatment of hernias were of the heavy type with a smaller pore size, greater weight/area, lesser elasticity and higher burst pressure. The latter generation of meshes included the light weight meshes with larger pore size resulting in smaller interface between the mesh and surrounding tissues, low weight per area, greater elasticity and a lower burst pressure. ${ }^{1}$

It has been surmised that the inflammatory reaction to the foreign material is correlated with the amount and structure, i.e. pore size of the synthetic material inserted. Tension free repair with non-absorbable mesh (Polypropylene) has been used in a higher number of cases during the past few years. ${ }^{1}$

Financial or Other, Competing Interest: None.

Submission 08-02-2016, Peer Review 04-03-2016,

Acceptance 09-03-2016, Published 18-03-2016.

Corresponding Author:

Dr. K. M. Ganesh Babu,

B1, Block 2, BSR Park Apartment,

Vijaya Bank Colony Extension,

Horamavu,

Bangalore-43.

E-mail: ganeshbabukm@gmail.com

DOI: $10.14260 /$ jemds $/ 2016 / 285$
The most important properties of meshes were found to be the type of filament, tensile strength and porosity. These determine the weight of the mesh and its biocompatibility. The tensile strength required is much less than originally presumed and light weighted meshes are thought to be superior due to their increased flexibility and reduction in discomfort. Large pores are also associated with a reduced risk of infection and shrinkage. When meshes are categorized by density, a mesh with density $>100 \mathrm{~g} / \mathrm{m}^{2}$ is accepted as heavy, whereas a $35-50 \mathrm{~g} / \mathrm{m}^{2}$ density is classified as light weight. ${ }^{2}$

\section{MATERIALS AND METHODS}

\section{Source of Data}

Study includes patients admitted in Surgery Department, MVJ and RH, Hoskote, Bangalore, for inguinal hernia; 60 patients admitted for Lichtenstein inguinal repair in Department of Surgery, MVJMC and RH.

\section{The Method of Study Consists of}

Detailed history taking and clinical examination as per the proforma investigations after taking written informed consent.

Patients who are undergoing elective Lichtenstein inguinal hernia repair are divided into two groups using randomization by equal allocation.

First group (A) consists of 30 patients in whom the light weight polypropylene mesh is used by Lichtenstein's technique of tension free mesh repair.

Second group (B) consists of 30 patients in whom the heavy weight propylene mesh is used by Lichtenstein's technique of tension free repair.

Patients have been followed up postoperatively at the end of 2 weeks, 1 month, 3 months, 6 months and 1 year for recurrence, foreign body sensation, pain and return to normal activities.

Patients complaining of persistent pain at the operative site during the $3^{\text {rd }}$ month followup will be considered as having 
chronic pain. Patients has been taken for ultrasonography on $2^{\text {nd }}, 3^{\text {rd }}, 4^{\text {th }}$ and $5^{\text {th }}$ followup visits for determining local tissue reaction/subclinical recurrence and mesh shrinkage.

\section{Inclusion Criteria}

Uni or bilateral inguinal hernia, age $>18$ years, hernia of all sizes.

\section{Exclusion Criteria}

Patients without consent, complicated inguinal hernias, recurrent hernias, femoral hernia, cases with previous history of explanation of mesh, patients with active infection in the inguinal region.

\section{Statistical Calculation}

Statistical calculations will be done by help of Chi-squared test with degree of significance $<5 \%$.

\section{RESULTS}

In this study, maximum patients were of age group 31-40 and 41-50 (Each 10) in heavy mesh group. In the light mesh group, maximum patients were in 31-40 age group (Each 15). Youngest patient being 24 years old and eldest being 71 years old in the whole sample size. Mean age of patients in heavy group is 41.70 and in light group is 44.10 .

In this study, total males are 55 and females are 5. In heavy mesh group, there are 26 males and 4 females. In light mesh group, there are 2 males and 1 female.
In both the groups, cases of right indirect hernia is more and only one case of bilateral direct, which is in light mesh group. There was no case of left direct hernia.

There were 6 patients in heavy mesh group with premorbid conditions and 5 in light mesh group. There were no patients with HBsAg or Hypoproteinaemia in light group.

There were more number of patients having unhealthy personal habits in heavy group, i.e. 6 than in light group i.e. 4 . There were 5 smokers in heavy mesh group and 2 in light mesh group. There were no alcoholics in light mesh group and no smoker and alcoholic in heavy mesh group.

\section{Foreign Body Sensation}

Foreign body sensation in heavy mesh group is significantly high; 9 patients in heavy mesh group had foreign body sensation in $2^{\text {nd }}$ week followup, whereas in light group it is 3 patients. In one month followup heavy mesh group had patients, whereas in light group it was 4 . In three months followup heavy mesh group had 8 patients, whereas light had 4 patients. In 6 months followup, heavy mesh group had 3 patients, whereas light mesh group had 2 patients. In one year followup, heavy mesh group had 1 patient and light mesh group had none.

\begin{tabular}{|c|c|c|c|c|c|c|}
\hline $\begin{array}{c}\text { Foreign Body } \\
\text { Sensation }\end{array}$ & $\begin{array}{c}\text { 2 Week } \\
\text { Follow-up }\end{array}$ & $\begin{array}{c}\text { 1 Month } \\
\text { Follow-up }\end{array}$ & $\begin{array}{c}\text { 3 Month } \\
\text { Follow-up }\end{array}$ & $\begin{array}{c}\text { 6 Month } \\
\text { Follow-up }\end{array}$ & $\begin{array}{c}\text { 1 Year } \\
\text { Follow-up }\end{array}$ & \% Change \\
\hline $\begin{array}{c}\text { Heavy } \\
\text { mesh n=30 }\end{array}$ & & & & & & \\
\hline No & $21(70 \%)$ & $21(70 \%)$ & $22(73.3 \%)$ & $27(90 \%)$ & $29(96.7 \%)$ & $27.7 \%$ \\
\hline Yes & $9(30 \%)$ & $9(30 \%)$ & $8(26.7 \%)$ & $3(10 \%)$ & $1(3.3 \%)$ & $-26.7 \%$ \\
\hline $\begin{array}{c}\text { Light } \\
\text { mesh n=30 }\end{array}$ & & & & & \\
\hline No & $27(90 \%)$ & $26(86.7 \%)$ & $26(86.7 \%)$ & $28(93.3 \%)$ & $30(100 \%)$ & $10 \%$ \\
\hline Yes & $3(10 \%)$ & $4(13.3 \%)$ & $4(13.3 \%)$ & $2(6.7 \%)$ & $0(0 \%)$ & $-10 \%$ \\
\hline p value & $0.053+$ & 0.117 & 0.197 & 1.000 & 1.000 & - \\
\hline
\end{tabular}

\section{Chi-square test/Fisher Exact test}
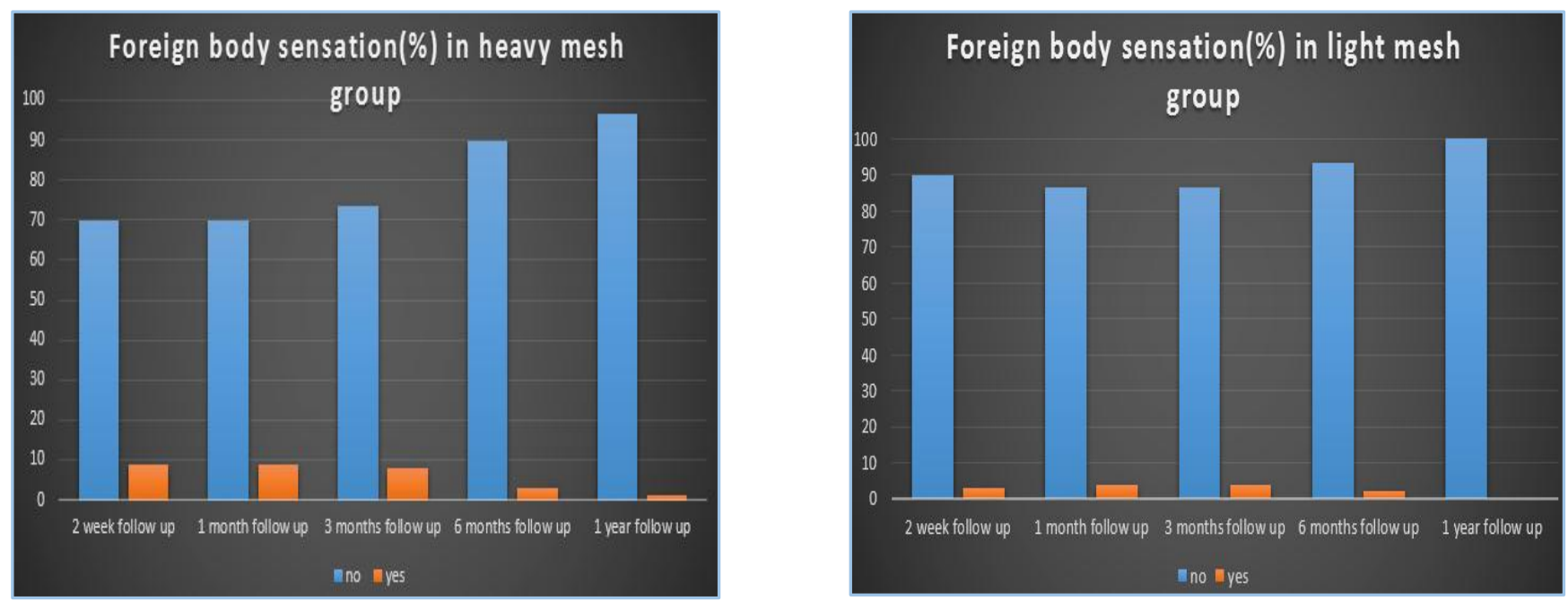


\section{Pain}

Chronic pain is considered in this study as pain which persists on or after $3^{\text {rd }}$ month followup. On $3^{\text {rd }}$ month followup, heavy mesh group had 7 patients with chronic pain, whereas in light mesh group there were 3 patients. On $6^{\text {th }}$ month followup heavy mesh group had 4 patients, whereas light mesh group had 2 patients. On one year followup heavy mesh group had 2 patients, whereas light mesh group had 1 patient.

\section{Stiffness over Abdominal Wall}

In the heavy mesh group, 3 patients had stiffness over abdominal wall in the $2^{\text {nd }}$ week followup, 3 in 1 month followup, 3 in 3 month's followup, 2 in 6 month's followup and nil in 1-year followup.

\section{Recurrence}

Two patients showed recurrence in heavy mesh group, one in 3-month followup and one in 6-month followup.

Four patients showed recurrence in light mesh group. One in 3-month followup, 3 in 6-month followup and one in 1year followup.

\begin{tabular}{|c|c|c|c|c|c|c|}
\hline Recurrence & $\begin{array}{c}\mathbf{2} \text { Week } \\
\text { Follow-up }\end{array}$ & $\begin{array}{c}\text { 1 Month } \\
\text { Follow-up }\end{array}$ & $\begin{array}{c}\text { 3 Months } \\
\text { Follow-up }\end{array}$ & $\begin{array}{c}\text { 6 Months } \\
\text { Follow-up }\end{array}$ & $\begin{array}{c}\text { 1 Year } \\
\text { Follow-up }\end{array}$ & \% Change \\
\hline Heavy mesh n=30 & & & & & & \\
\hline No & $30(100 \%)$ & $30(100 \%)$ & $29(96.7 \%)$ & $29(96.7 \%)$ & $30(100 \%)$ & $0.0 \%$ \\
\hline Yes & $0(0 \%)$ & $0(0 \%)$ & $1(3.3 \%)$ & $1(3.3 \%)$ & $0(0 \%)$ & $0.0 \%$ \\
\hline Light mesh n=30 & & & & & & \\
\hline No & $30(100 \%)$ & $30(100 \%)$ & $29(96.7 \%)$ & $27(90 \%)$ & $29(96.7 \%)$ & $-3.3 \%$ \\
\hline Yes & $0(0 \%)$ & $0(0 \%)$ & $1(3.3 \%)$ & $3(10 \%)$ & $1(3.3 \%)$ & $3.3 \%$ \\
\hline pvalue & 1.000 & 1.000 & 1.000 & 0.612 & 1.000 & - \\
\hline
\end{tabular}

\section{Chi-square test/Fisher Exact test}
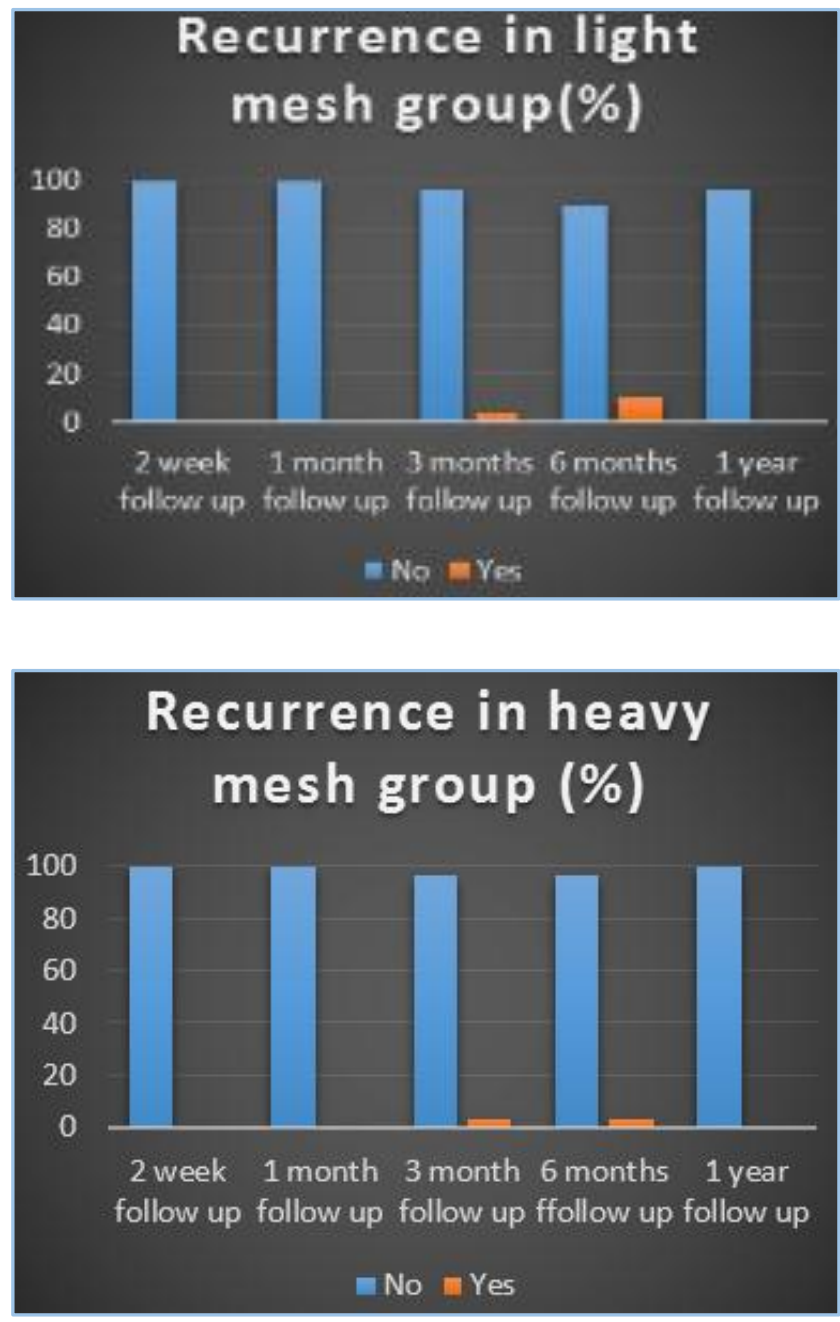

\section{DISCUSSION}

In this comparative study between light and heavy polypropylene mesh in Lichtenstein repair of inguinal hernia, which was conducted in MVJ Medical College and Research Hospital, Hoskote, Bangalore.

Total of 60 patients were studied; 30 patients each were allocated in heavy and light mesh group respectively.

In a study conducted by Keith Rose, David Wright, et al. done at University, Department of Surgery, South Manchester University Hospital, West Didsbury, Manchester, UK, where the outcome of 200 consecutive patients with inguinal hernias repaired by the tension free mesh technique at a specialist clinic was assessed one year after operation. ${ }^{3}$

Of the total, 118 patients were discharged on the day of operation and 60 the following morning. There were no unplanned overnight stays and no readmissions; 54 patients had no pain the day after operation. A further 53 had pain for upto 5 days, 38 for upto 10 days and 33 for over 10 days; 27 patients had returned to normal activity within 7 days, 73 within 2 weeks and 145 within a month of operation. ${ }^{3}$

Lichtenstein published a personal series of 6321 repairs of which $21.3 \%$ were for recurrence and found a recurrence rate of $0.7 \%$ after a minimum followup of 2 years. 4

In a study done by Kark AE and Kurzer M of British Hernia Centre, London. ${ }^{5}$ the technical problems, early complications and short term results of a tension free method inguinal hernia repairs (Lichtenstein's repair) in 1017 patients have been assessed.

In this study of the total patients, $21.3 \%$ required no pain killers after the first night; $59.2 \%$ took oral analgesia for 1-7 days (13.2\% upto 3 days and $46 \%$ for $4-7$ days). Thus, after 1 week $80 \%$ of patients required no further analgesia. Neuritic type of pain in the groin at any point from the anterior superior spine to the upper scrotum and thigh persisted in 10 patients. Pain of this type persisted beyond a 6 -month period in 8 patients and gradually disappeared over the next. 512 months

Just $\mathrm{E}$ and Botet $\mathrm{X}$, et al. in their study titled reduction of complication rate in Lichtenstein hernia repair done in Department of General Surgery, Hospital Alt Penedes, Barcelona, Spain, found that out of overall cases operated 155 (7.7\%) wounds developed complications, 74 of which (3.7\%) were hematomas, $44(2.2 \%)$ infections, $27(1.3 \%)$ seromas and $10(0.5 \%)$ were complications from other causes. ${ }^{6}$ 
Konrad Pielacinski, Andrzej B. Szczcepanik, et al. in their study done in Warsaw, Poland, discussed that although tension free surgical techniques for inguinal hernia repair have contributed to the improvement of the outcomes as well as the marked reduction of hernia recurrence. These techniques are not free of complications. The most common and still unresolved clinical problem is the chronic pain in the operated groin. One of the likely reasons, which are taken into account is the presence of the mesh and its type.

Research data show that the amount and structure of the implanted material have a significant influence on scar tissue formation. Heavy propylene non-absorbable meshes cause a more intense inflammatory reaction and scar formation than the light propylene or partially absorbable meshes. The implied superiority of light meshes was confirmed in clinical trials, but with relatively short followup periods. ${ }^{7}$

The study also concluded that both the light and the heavy, non-absorbable mesh used in the Lichtenstein's technique are equally effective for prevention of inguinal hernia recurrence. Light vs. heavy, non-absorbable mesh results in lower intensity of chronic pain, lower risk and intensity of postoperative ailments, faster return to normal activities of daily living and intensity of postoperative ailments, faster return to normal activities of daily living and sport as well higher satisfaction with treatment.

The type of mesh has no effect on surgery duration, risk of intraoperative and early postoperative complications or pain intensity in the early postoperative period. Individuals patients' characteristics such as body mass, general condition, type of hernia, surgery duration and operator have a significant effect on the risk of the intraoperative damage, percentage of early complications, return to normal activities of daily living, chronic pain, ailments in the operated groin and patient's satisfaction with treatment. ${ }^{7}$

Lloyd D. McLean in his editorial "Repair of Inguinal Hernia" said that excellent results with very low recurrence rates (Less than $5 \%$, frequently less than $1 \%$ ) have been reported for primary repair of inguinal hernias by these techniques by surgeons with large experience and dedicated interest. 8

\section{CONCLUSION}

The Comparative Study Between Light and Heavy

Polypropylene Mesh in Lichtenstein Repair of Inguinal

Hernia Concluded as,

1. Light mesh has less incidence of stiffness over abdominal wall postoperatively in comparison to heavy mesh.

2. Light mesh has less incidence of foreign body sensation postoperatively than heavy mesh.

3. Light mesh has less incidence and lesser severity of chronic pain than heavy mesh.

4. Heavy mesh has lower recurrence rates than light mesh.

\section{REFERENCES}

1. Khan N, Bangash A, Muzaffaruddin S, et al. Polygalactine/polypropylene mesh vs. propylene mesh: is there a need for newer prosthesis in inguinal hernia? Saudi J Gastroenterol 2010;16(1):8-13. doi:10.4103/1319-3767.58761.

2. Brown CN, Finch JG. Which mesh for hernia repair. Ann R Coll Surg Engl 2010;92:272-278.

Doi 10.1308/003588 410X1266419 2076296.

3. Keith Rose, David Wright, Tony Ward, et al. Tension-free mesh hernia repair: recovery and recurrence after one year. Ann R Coll Surg Engl 1999;81:329-332.

4. Lichtenstein IL. Herniorrhaphy. A personal experience with 6321 cases. Am J surg 1987;153:553-9.

5. Kark AE, Kurzer M, Waters KJ. Tension-free mesh hernia repair: review of 1098 cases using local anaesthesia in a day unit. Ann R Coll Surg Engl 1995;77:299-304.

6. Just E, Botet $\mathrm{X}$, Martinez $\mathrm{S}$, et al. Reduction of the complication rate in lichtenstein hernia repair. Int J Surg 2010;8(6):462-5.

doi:10.1016/j.ijsu.2010.06.006.

7. Konrad Pielcinski, Andrzej B Szczepanik, Tadeusz Wroblewski. Effect of mesh type, surgeon and selected patients' characteristics on the treatment of inguinal hernia with the lichtenstein technique: randomized trial. Video surgery Miniinv 2013;8(2):99-106. DOI: 10.5114/wiitm.2011.32824.

8. Llyod D MacLean. The repair of inguinal hernias. Ann Surg 1995;221(1):1-2. 